\title{
EKSISTENSI DAN PERANAN KEPALA DINAS KESEHATAN DALAM MENINGKATKAN PELAYANAN KESEHATAN DI PROVINSI ACEH
}

\author{
Cut Khairunnisa* \\ Bagian Ilmu Kesehatan Masyarakat Fakultas Kedokteran Universitas Malikussaleh \\ Jln. H.Meunasah Uteunkot Cunda Lhokseumawe, \\ *Corresponding Author: icut_nisa@yahoo.com
}

\begin{abstract}
ABSTRAK
Kinerja pimpinan dan tenaga kesehatan merupakan masalah yang sangat penting untuk dikaji dalam rangka mempertahankan dan meningkatkan pembangunan kesehatan. Dalam bidang kesehatan, salah satu pemimpin struktural dalam tatakelola pemerintahan daerah adalah Kepala Dinas Kesehatan yang berwenang menjalankan unit kerja Dinas Kesehatan sebagai institusi yang bergerak di bidang pelayanan kesehatan. Eksistensi dan peranan kepala Dinas Kesehatan sangat penting dan berpengaruh terhadap pelaksanaan tujuan instansi tersebut. Dalam aspek pelayanan kesehatan di provinsi Aceh, Undang-Undang No. 11 Tahun 2006 Tentang Pemerintah Aceh (UUPA) memberikan kewenangan kepada pemerintah Aceh untuk mengatur dan menyelenggarakan pelayanan kesehatan sesuai dengan asas dan prinsip yang dianut oleh daerah tersebut. Pembangunan kesehatan di Aceh didasari pada nilai-nilai perikemanusiaan (humanity), pemberdayaan (empowerment) dan kemandirian (independency), adil dan merata (equity), pengutamaan (quality) dan manfaat (beneficiary) dengan target yang sejalan dengan kearifan lokal (syariat Islam dan adat istiadat) yang ada. Kepala Dinas Kesehatan harus mampu mewujudkan perubahan dilingkungannya, membangun komunikasi dan jaringan kerja yang efektif, mampu mempengaruhi orang, menerima keragaman, mempunyai komitmen, keteladanan, kedisiplinan, kepamrihan kerja, keoptimisan, tindakan saling mengasihi, dan kekonsistenan yang saling berdampak positif. Kepala Dinas Kesehatan di Aceh idealnya mempunyai kompetensi dibidang ilmu kesehatan sehingga mampu membawa perubahan ke arah yang lebih baik karena salah satu efektifitas kerja pimpinan akan diukur dari kompetensi keilmuannya.
\end{abstract}

Kata Kunci: eksistensi; kepala dinas kesehatan; pelayanan kesehatan 


\title{
EXISTENCE AND THE ROLE OF THE HEAD OF HEALTH IN IMPROVING HEALTH CARE IN THE PROVINCE OF ACEH
}

\begin{abstract}
Performance management and health personnel are a very important issue to be studied in order to maintain and improve the health development. In the health field, Head of Department of Health is one of the leaders in local governance structural authorized units led Health Department. The existence and role of the head of Department of Health is very important and affect the implementation of the objectives of the institution. In the aspect of health care in the province, Law No. 11 Year 2006 concerning the Government of Aceh (UUPA) gives authority to the Aceh government to regulate and organize health services in accordance with the principles adopted by the region. Health development in Aceh based on the values of humanism, empowerment and independence, fair and equitable, prioritizing and benefits with targets in line with local knowledge (Islamic law and customs) exist. Head of Health Department should be able to realize the changes in their environment, develop communication and effective working network, able to influence people, embrace diversity, are committed, exemplary, disciplined, selfless, optimism, compassion mutual action, and consistency that have a positive impact. Head of the Health Office in Aceh ideally have competence in the field of health sciences so as to bring change for the better because one measured the effectiveness of the leadership of scientific competence.
\end{abstract}

Keywords: existence; head of Department of Health; health services 


\section{Pendahuluan}

Kinerja pimpinan dan tenaga kesehatan merupakan masalah yang sangat penting untuk dikaji dalam rangka mempertahankan dan meningkatkan pembangunan kesehatan. Pembangunan kesehatan diarahkan untuk meningkatkan kesadaran, kemauan, dan kemampuan hidup sehat bagi setiap orang agar peningkatan derajat kesehatan masyarakat yang setinggi-tingginya dapat terwujud. Pembangunan kesehatan diselenggarakan dengan berdasarkan pada perikemanusiaan, pemberdayaan dan kemandirian, adil merata, serta pengutamaan dan manfaat dengan perhatian khusus pada penduduk rentan, antara lain ibu, bayi, anak, lanjut usia (lansia) dan keluarga miskin. Salah satu dimensi yang penting dalam merealisasi tujuan adalah kemimpinan.

Kepemimpinan mutlak diperlukan dimana terjadi interaksi kerjasama antara dua orang atau lebih dalam menjalankan kegiatan dalam sebuah organisasi. Kepemimpinan menentukan arah dan tujuan serta bimbingan dalam melaksanakan pekerjaan. Gaya kepemimpinan yang sesuai dengan keinginan pegawai akan membuat pegawai merasa nyaman ketika bekerja dan pegawai akan lebih bersemangat ketika bekerja. Semangat kerja pegawai dapat menunjang pencapaian tujuan dan sasaran instansi Karena semangat kerja dapat mendorong pegawai untuk bekerja lebih giat dan lebih baik.

Gaya kepemimpinan atasan mempunyai peranan yang cukup penting dalam meningkatkan disiplin kerja pegawai dalam melaksanakan tugasnya sehari-hari. Kemampuan dan keterampilan kepemimpinan (leadership) untuk mengarahkan merupakan faktor penting dalam efektivitas pimpinan. Pada gaya kepemimpinan faktor penting pimpinan tidak bisa terlepas dari kepribadiannya yang telah dipengaruhi oleh lingkungan atau pendidikan dan kultur sosial. Gaya kepemimpinan atasan didefinisikan sebagai kemampuan yang dipunyai seseorang untuk mempengaruhi orang lain agar bekerja mencapai tujuan dan sasaran tertentu. Disiplin kerja erat kaitannya dengan motivasi kerja sehingga makin tinggi disiplin kerja menunjukan motivasi kerja yang tinggi pula.

Konstitusi Organisasi Kesehatan Dunia (WHO, 1948), Undang-Undang Dasar 1945 Pasal $28 \mathrm{H}^{1}$ dan Undang-Undang Nomor 36 Tahun 2009 tentang Kesehatan menegaskan bahwa kesehatan adalah hak fundamental setiap warga $^{2}$. Oleh karena itu setiap individu, keluarga dan masyarakat berhak memperoleh perlindungan terhadap kesehatannya dan negara bertanggung jawab mengatur agar terpenuhi hak hidup sehat bagi penduduknya. Untuk mewujudkan hak-hak kesehatan masyarakat tersebut diperlukan pimpinan yang mempunyai kompetensi dan profesional pada bidang kesehatan sehingga programprogram yang akan dijalankan dapat menyentuh sasaran sesuai dengan kebutuhan masyarakat.

Dalam bidang kesehatan, salah satu pemimpin struktural dalam tatakelola pemerintahan daerah adalah Kepada Dinas Kesehatan yang berwenang menjalankan unit kerja Dinas Kesehatan sebagai institusi yang bergerak di bidang pelayanan kesehatan kepada masyarakat di wilayah provinsi maupun kabupaten/kota. Peranan kepala Dinas Kesehatan sangat penting dan berpengaruh terhadap pelaksanaan tujuan instansi tersebut, yaitu untuk meningkatkan pelayanan terhadap para masyarakat terutama dalam proses pengawasan dan pembinaan terhadap kebutuhan pelayanan kesehatan yang baik dan berkualitas. Namun, pada kenyataannnya ada beberapa Kepala Dinas Kesehatan di wilayah Provinsi Aceh seperti Kabupaten Aceh Tamiang, Kabupaten Nagan Raya, Kabupaten Aceh 
Utara dan Kota Lhokseumawe pernah di pimpin oleh Kepala Dinas yang tidak mempunyai kompetensi di bidang kesehatan. Hal ini menjadi menarik untuk dikaji, sejauh mana peranan kepala dinas kesehatan dalam meningkatkan kualitas pelayanan kesehatan kepada masyarakat?

\section{Metode penelitian}

Pengkajian terhadap eksistensi dan peranan pimpinan struktural dan tatakelola dalam pemerintahan aceh di bidang kesehatan dilakukan secara kualitatif dengan menelaah peraturan-peraturan yang terkait dengan bidang kesehatan.

\section{Hasil dan Pembahassan}

\section{Konsep dan Definisi Kepemimpinan}

Pemimpin adalah mereka yang hanya dapat mengerjakan apa yang harus mereka kerjakan dengan dukungan kelompoknya, yang harus tergerak atau dibujuk untuk mengikuti mereka. Karena itu, kepemimpinan adalah sesuatu mengenai mendorong dan membangkitkan individu dan kelompok untuk berusaha sebaikbaiknya demi mencapai hasil yang diinginkan. Peran kepemimpinan sangat strategis dan penting dalam sebuah organisasi.

\section{Menurut Armstrong} kepemimpinan adalah mengerjakan segala sesuatu melalui orang lain jika ada sasaran untuk dicapai, jika suatu tugas harus dilaksanakan dan jika lebih dari satu orang diperlukan untuk melakukannya. ${ }^{3}$ Maxwell (1995) menyimpulkan bahwa setiap orang masing-masing mempengaruhi dan dipengaruhi orang lain. Itu berarti bahwa semua orang memimpin dalam beberapa bidang, sementara dalam bidang lain seseorang dipimpin. Kepemimpinan yang sesungguhnya lebih dari hanya memiliki wewenang tetapi menjadi orang yang diikuti orang lain dengan senang hati dan penuh keyakinan. ${ }^{4}$
Menurut Kadarusman kepemimpinan (Leadership) dibagi tiga, yaitu: (1) Self Leadership; (2) Team Leadership; dan (3) Organizational Leadership. Self Leadership yang dimaksud adalah memimpin diri sendiri agar jangan sampai gagal menjalani hidup. Team Leadership diartikan sebagai memimpin orang lain. ${ }^{5}$

Pemimpinnya dikenal dengan istilah team leader (pemimpin kelompok) yang memahami apa yang menjadi tanggung jawab kepemimpinannya, menyelami kondisi bawahannya, kesediaannya untuk meleburkan diri dengan tuntutan dan konsekuensi dari tanggung jawab yang dipikulnya, serta memiliki komitmen untuk membawa setiap bawahannya mengeksplorasi kapasitas dirinya hingga menghasilkan prestasi tertinggi. Sedangkan organizational leadership dilihat dalam konteks suatu organisasi yang dipimpin oleh organizational leader (pemimpin organisasi) yang mampu memahami nafas bisnis perusahaan yang dipimpinnya, membangun visi dan misi pengembangan bisnisnya, kesediaan untuk melebur dengan tuntutan dan konsekuensi tanggung jawab sosial, serta komitmen yang tinggi untuk menjadikan perusahaan yang dipimpinnya sebagai pembawa berkah bagi komunitas baik di tingkat lokal, nasional, maupun internasional.

Gaya kepemimpinan pada dasarnya mengandung pengertian sebagai suatu perwujudan tingkah laku dari seorang pemimpin yang menyangkut kemampuannya dalam memimpin. Perwujudan tersebut biasanya membentuk suatu pola atau bentuk tertentu. Pengertian gaya kepemimpinan yang demikian ini sesuai dengan pendapat yang disampaikan oleh Newstrom (1995) yang menyatakan bahwa pola tindakan pemimpin secara keseluruhan seperti yang dipersepsikan atau diacu oleh bawahan. Gaya kepemimpinan mewakili filsafat, 
ketrampilan, dan sikap pemimpin dalam politik. Gaya kepemimpinan adalah pola tingkah laku yang dirancang untuk mengintegrasikan tujuan organisasi dengan tujuan individu untuk mencapai tujuan tertentu. ${ }^{6}$

Wirawan (2009) berpandangan bahwa karakteristik hubungan tugas bahwa pemimpin memiliki ciri-ciri kebutuhan akan berprestasi yang tinggi, orientasi dan uraian tugas yang tinggi akan mempengaruhi persepsi kepemimpinan dengan kinerja, sekaligus juga akan berpengaruh terhadap tingkat disiplin pegawai. ${ }^{7}$

Kepemimpinan dalam suatu organisasi merupakan suatu faktor yang menentukan atas berhasil tidaknya suatu organisasi atau usaha. Kepemimpinan yang sukses menunjukkan bahwa pengelolaan suatu organisasi berhasil dilaksanakan dengan sukses pula. Seorang pemimpin yang baik adalah seorang yang tidak melaksanakan sendiri tindakan yang bersifat operasional, tetapi mengambil keputusan, menentukan kebijaksanaan dan mengarahkan orang lain untuk melaksanakan keputusan yang diambil sesuai dengan kebijaksanaan yang telah digariskan. ${ }^{8}$

\section{Teori Kepemimpinan}

Teori kepemimpinan tersebar dalam banyak versi sesuai dengan karakteristik sebuah profesi. Salah satu teori kepemimpinan yang pertama adalah teori sifat atau teori ciri pembawaan (stogdill, 1948, 1974; Ghiselli, 1963, 1971; Argyris, 1970; Lundin, 1973) yang memaparkan intelegensia, kepribadian, serta kemampuan seseorang. Pada era 1990-an akhir dan era 2000 awal, maka muncul teori kepemimpinan seperti primal leadership, change leader, level 5 leadership, exemplary leadership, extraordinary leadership, principlecentered Leadership, dan masih banyak terdapat teori kepemimpinan lainnya sesuai dengan perkembangan ilmu pengetahuan dan teknologi.

Primal Leadership: Pendekatan dari Sisi Kecerdasan Emosional

Cukup banyak upaya yang dilakukan oleh berbagai pakar untuk menggambarkan model kepemimpinan dengan baik. Ada model yang diberikan oleh Daniel Goleman, McKee, dan Boyatzis yang terkenal dengan teori primal leadership. ${ }^{9}$ Teori primal leadership ini lebih melihat kepemimpinan dari sisi kecerdasan emosional (emotional intelligence). Ini tidaklah mengherankan karena mereka adalah murid dari David McClelland yang merupakan perintis riset di bidang kecerdasan emosional. ${ }^{10}$

Mereka menyarankan agar pemimpin melengkapi amunisi gaya kepemimpinannya agar mampu menghadapi berbagai situasi yang berbeda secara efektif dengan gaya kepemimpinan yang sesuai. Mereka menyimpulkan bahwa terdapat enam gaya kepemimpinan yang berdasarkan kepada kecerdasan emosional, yaitu Gaya koersif (coercive), Gaya otoritatif (authoritative or visionary), Gaya afiliatif (affiliative), Gaya demokratik (democratic), Gaya penentu standar (pacesetting), Gaya pelatih (coaching).

\section{Leader-Participation Model}

Leader-Participation Model ditulis oleh Vroom dan Yetton (1973). Model ini melihat teori kepemimpinan yang menyediakan seperangkat peraturan untuk menetapkan bentuk dan jumlah peserta pengambil keputusan dalam berbagai keadaan. Teori Yetton dan Vroom mengemukakan bahwa kepuasan dan prestasi disebabkan oleh perilaku bawahan yang pada gilirannya dipengaruhi oleh perilaku atasan, karakteristik bawahan, dan faktor lingkungan. ${ }^{11}$ 


\section{Teori Situasional}

Teori situasional yang paling dikenal adalah teori Hersey dan Blanchard (1974) yang menekankan pada gaya kepemimpinan dan kesiapan para bawahan yang harus cocok. Teori ini juga didasarkan pada tinggi rendahnya perilaku hubungan dan tinggi rendahnya perilaku tugas menuju efektivitas. ${ }^{12}$

\section{Teori Perilaku (Behaviour)}

Teori perilaku adalah teori kepemimpinan yang menjelaskan ciri-ciri perilaku seorang pemimpin dan ciri-ciri perilaku seorang bukan pemimpin. Ada berbagai aliran dan teori perilaku:

a. Aliran Ohio State University atau mashab yang berkembang di Ohio State University dikenal dengan Ohio State Studies, membedakan kepemimpinan dari segi struktur dan hubungan antar manusia;

b. University of Michigan Di University of Michigan diikuti pula aliran perilaku yang dikenal dengan University of Michigan Studies. Studi Michigan ini membedakan antara pemimpin yang berorientasi pada karyawan atau berorientasi pada hubungan antarpribadi dan pemimpin yang berorientasi pada produksi dan tugas;

c. The Managerial Grid, Teori kepemimpinan yang dikenal dengan kisi-kisi manajerial atau The Managerial Grid yang merupakan tulisan Blake dan Mouton (1964) membagi kepemimpinan dalam sebuah matriks, di mana garis vertikal atau ordinat melihat pada pertimbangan manusia dan garis horizontal serta absis melihat pada produksi. Di Skandinavia terdapat pula Scandinavian Studies yang melihat pemimpin yang berorientasi pada pembangunan dan pengembangan atau yang mencari gagasan baru serta menciptakan dan menerapkan perubahan. ${ }^{13}$

Level 5 Leadership: Pendekatan dari Sisi Kematangan Karakter

Jim Collins, seorang pakar manajemen yang terkenal dengan bukunya "Good to Great" (Collins, 2001), melakukan riset yang mendalam untuk melihat bagaimana perusahaan-perusahaan di Amerika Serikat sanggup mentransformasikan dirinya dari baik (good) menjadi luar biasa (great) dengan segala kriterianya. Hasil riset selama hampir 6 tahun tersebut menyimpulkan ada 3 komponen utama yang menyebabkan hal itu terjadi, yaitu discipline people, discipline thought, dan discipline actions. Salah satu dari komponen discipline people adalah kepemimpinan tingkat kelima atau level 5 leadership. ${ }^{14}$

Lima tingkat kepemimpinan dalam model kepemimpinan yang dipaparkan oleh Jim Collins tersebut, dengan kepemimpinan tingkat ke- 5 yang paling tinggi adalah:

a. Tingkat 1: Individu yang kompeten, membangun produktifitas kerja yang tinggi melalui pengetahuan, ketrampilan, bakat, dan motivasi kerja yang tinggi;

b. Tingkat 2: Mampu bekerja sama dengan orang lain di dalam sebuah kelompok kerja, dan mampu berkontribusi secara positif demi kemajuan bersama;

c. Tingkat 3: Manajer yang kompeten, mampu memimpin sebuat tim, mendefinisikan sasaran dengan jelas, dan mampu menggerakkan orang dan sumber daya lainnya untuk mencapai sasaran tersebut dengan baik;

d. Tingkat 4: Pemimpin yang efektif, mampu membangun visi ke depan dengan baik dan jelas, mampu membangun komitmen manusia yang dipimpinnya dan menerapkan suatu standar kinerja yang tinggi; 
e. Tingkat 5: Membangun keberhasilan yang luar biasa dengan sikap rendah hati dan profesionalisme yang tinggi. Dari model kepemimpinan ini, Jim Collins menekankan dua unsur yang penting dalam tingkat kepemimpinan yang tertinggi yaitu sikap rendah hati dan professional.

\section{Extraordinary Leadership: Pendekatan dari Sisi Kompetensi}

Model kepemimpinan lain yang patut disimak adalah yang dihasilkan dari riset yang dilakukan oleh Zenger dan Folkman ${ }^{15}$. Zenger dan Folkman kelihatan sangat dipengaruhi oleh riset yang dilakukan oleh Jim Collins mengenai Level 5 Leadership dan juga oleh pendekatan kompetensi yang dikembangkan oleh David McClelland dan Lyle M. Spencer. Dalam model yang mereka sebut sebagai Extraordinary Leadership tersebut, mereka mengemukakan ada 4 (empat) hal yang harus dimiliki oleh seorang pemimpin, yaitu: ${ }^{16}$

a. Kemampuan atau kapabilitas personal (personal capability). Seorang pemimpin yang hebat itu memiliki kemampuan personal yang luar biasa, mulai dari kemampuan berpikir, berbagai soft competency, sampai dengan kemampuan teknis tertentu. Karena kemampuan yang tinggi ini, maka dia akan dihormati dan disegani oleh bawahannya;

b. Fokus kepada hasil (focus on results). Seorang pemimpin yang hebat itu tidak akan mendiktekan segala sesuatunya kepada bawahannya. Dia akan melakukan pemberdayaan, mulai dengan mengembangkan kompetensi bawahan, sehingga mampu mencari jalan untuk menyelesaikan pekerjaan dengan kinerja tinggi. Dia hanya akan mengendalikan bawahannya melalui hasil akhir, bukan pada proses. Ini berarti pemberdayaan, sekaligus sikap mempercayai bawahan;

c. Memimpin perubahan organisasi (leading organizational change). Seorang pemimpin yang hebat itu sanggup membawa perubahan terhadap organisasi sesuai dengan perubahan tuntutan situasi. Dia tidak terjebak di dalam zona nyaman, yang mampu "membunuh" organisasi secara perlahan-lahan. Perubahan dilakukan bukan asal berubah, melainkan perubahan yang bertujuan untuk kebaikan bersama, perubahan yang terstruktur rapi dengan suatu manajemen perubahan yang baik, dan sedapat mungkin menekan dampak negatif yang timbul akibat perubahan tersebut;

d. Keterampilan antar manusia atau interpersonal (interpersonal skills). Seorang pemimpin yang hebat itu memiliki kemampuan interpersonal yang baik, mulai dari memahami orang lain, menyampaikan pesan, mengayomi, memberikan pujian kepada bawahan, bersikap tegas, dan tidak mengutamakan popularitas pribadi.

\section{Eksistensi Pemimpin Pada Bidang Kesehatan dalam Tatakelola Pemerintahan Daerah Provinsi Aceh}

Dalam Pasal $28 \mathrm{H}$ ayat (1) UndangUndang Dasar Negara Republik Indonesia Tahun 1945 telah ditegaskan bahwa setiap orang berhak memperoleh pelayanan kesehatan, kemudian dalam Pasal 34 ayat (3) dinyatakan negara bertanggung jawab atas penyediaan fasilitas pelayanan kesehatan dan fasilitas pelayanan umum yang layak.

Untuk menjamin terlaksananya pelayanan kesehatan yang baik dan berkualitas ditentukan oleh banyak faktor salah satunya adalah pemimpin di setiap unit kerja yang berhubungan dengan dunia kesehatan. Eksistensi pemimpin dalam 
pelaksanaan pelayanan kesehatan mempunyai pengaruh penting dalam mewujudkan suatu efektivitas pelayanan kesehatan sesuai dengan standar kualitas pelayanan kesehatan yang baik dan bermartabat.

Salah satu pimpinan struktural yang mempunyai peranan penting dalam pelayanan kesehatan di daerah adalah Kepala Dinas Kesehatan pada peringkat wilayah Provinsi dan Kabupaten/Kota di Indonesia. Dalam Undang-Undang Nomor 23 Tahun 2014 tentang Pemerintahan Daerah (Undang-Undang No. 9 Tahun 2015 tentang Perubahan Kedua Atas UndangUndang No. 23 Tahun 2014 tentang Pemerintahan Daerah) menyebutkan bahwa salah satu kewenangan Pemerintah Daerah Provinsi dan Kabupaten/Kota adalah mengembangkan kualitas Sumber Daya Manusia (SDM) Tenaga Kesehatan. ${ }^{17}$ Kepala Dinas Kesehatan salah satu unit kerja dalam tata kelola pemerintahan daerah mempunyai kewenangan dan tangunggjawab untuk mengatur pemerataan tenaga kesehatan dalam menjalankan pelayanan kesehatan dan membuat perencanaan serta pengembangan SDM kesehatan untuk Upaya Kesehatan Masyarakat (UKM) dan Upaya Kesehatan Perorangan (UKP) daerah provinsi.

Dalam Undang-Undang Pemerintahan Daerah tersebut juga memberikan kewenangan kepada Pemerintah Daerah Provinsi untuk menerbitkan izin pendirian rumah sakit kelas B, C dan D sesuai dengan jenjang kewilayahan. Rumah Sakit publik yang dikelola Pemerintah Daerah diselenggarakan berdasarkan pengelolaan Badan Layanan Umum atau Badan Layanan Umum Daerah sehingga penerbitan izin pendirian rumah sakit harus mendapat klasifikasi dan perivikasi Dinas Kesehatan berdasarkan dengan Undang-Undang No. 44 Tahun 2009 Tentang Rumah Sakit dan aturan teknis lainnya. ${ }^{18}$
Dalam aspek pelayanan kesehatan di provinsi Aceh, Undang-Undang No. 11 Tahun 2006 Tentang Pemerintah Aceh (UUPA) memberikan memberikan kewenangan kepada pemerintah Aceh untuk mengatur dan menyelenggarakan pelayanan kesehatan sesuai dengan asas dan prinsip yang dianut oleh daerah tersebut. ${ }^{19}$ Dalam Pasal 224 UUPA disebutkan bahwa setiap penduduk Aceh mempunyai hak yang sama dalam memperoleh pelayanan kesehatan dalam rangka mewujudkan derajat kesehatan yang optimal. Namun, pelayan kesehatan tersebut harus sesuai dengan syariat islam sebagai landasan falsafah dalam pemerintahan provinsi Aceh. Hal ini disebutkan dalam Pasal 225 UUPA bahwa Pemerintah Aceh dan pemerintah kabupaten/kota wajib memberikan pelayanan kesehatan berdasarkan standar pelayanan minimal sesuai dengan peraturan perundang-undangan, sepanjang tidak bertentangan dengan syari' at Islam.

Instrumen yang bersifat teknis terhadap pelayanan kesehatan di Aceh diatur dalm Qanun Aceh No. 4 Tahun 2010 tentang kesehatan menyebutkan bahwa Dinas Kesehatan adalah perangkat daerah sebagai unsur pelaksanaan__Pemerintah Daerah di bidang Kesehatan, yang berada di bawah Gubernur sehingga eksistensi Kepala Dinas Kesehatan mempunyai tugas melaksanakan Tugas umum pemerintah, pembangunan dan pembinaan masyarakat di bidang Kesehatan. ${ }^{20}$

\section{Peranan Kepala Dinas Kesehatan Dalam Meningkatkan Pelayanan Kesehatan di Aceh}

Undang-Undang Nomor 11 Tahun 2006 tentang Pemerintahan Aceh, secara tegas menyatakan bahwa pembangunan di bidang kesehatan di Aceh dilaksanakan secara berkelanjutan yang bertujuan untuk meningkatkan taraf hidup dan kemakmuran rakyat. ${ }^{19}$ Pembangunan kesehatan di Aceh 
didasari pada nilai-nilai perikemanusiaan (humanity), pemberdayaan (empowermant) dan kemandirian (independency), adil dan merata (equity), pengutamaan (quality) dan manfaat (beneficiary) target yang sejalan dengan kearifan lokal (syariat Islam dan adat istiadat) yang ada. Dengan demikian seluruh penduduk Aceh mempunyai kesempatan dan kemandirian untuk hidup dalam lingkungan dan dengan perilaku hidup sehat, memiliki kemampuan untuk menjangkau pelayanan kesehatan yang bermutu secara adil dan merata serta memiliki derajat kesehatan yang setinggitingginya.

Pemerintah Aceh dalam kedudukannya sebagai wakil pemerintah berupaya mengaplikasikan hak fundamental penduduk Aceh bidang kesehatan tersebut dengan menanggung biaya terhadap pelayanan kesehatan dasar, pelayanan kesehatan rujukan di rumah sakit umum kelas III dan pelayanan kesehatan penunjang. Pembiayaan kesehatan bagi penduduk Aceh tentunya tetap berpatokan pada pelayanan kesehatan yang adil, merata, bermutu dan terjangkau.

Untuk mewujudkan semua tujuan tersebut, pemerintah aceh membentuk unit kerja yang membidangi bagian kesehatan yaitu Dinas Kesehatan yang dipimpin oleh Kepala Dinas Kesehatan sebagai perpanjangtangan pemerintah daerah dalam menjalankan berbagai program kesehatan dan bekerjasama dengan staek holder yang terkait. Sebagai salah satu daerah konflik dan bencana maka penanggulangan kesehatan harus disikapi dengan arif dan bijaksana serta tepat sasaran. Hal ini hanya dapat dilakukan apabila pimpinan pemerintah daerah dalam hal ini diwakili oleh kepala dinas kesehatan mempunyai kompetensi yang handal, profesional dan berpengalaman.

Berdasarkan Susunan Organisasi Dan Tata Kerja Dinas Kesehatan Propinsi Aceh, secara umum tugas dari Kepala Dinas
Kesehatan adalah melaksanakan tugas umum pemerintah, pembangunan dan pembinaan masyarakat di bidang Kesehatan. Dalam menyelnggarakan tugas tersebut, fungsi dari dinas kesehatan adalah:20

a. Pelaksanaan pembinaan umum di bidang kesehatan meliputi bidang peningkatan upaya kesehatan (promotif), pencegahan penyakit (preventif), pengobatan (kuratif) dan pemulihan kesehatan (rehabilitatif) sesuai dengan ketentuan yang berlaku;

b. Perumusan perencanaan dan kebijaksanaan teknis di bidang kesehatan sesuai dengan kebijaksanaan yang ditetapkan oleh Gubernur;

c. Pelaksanaan pembinaan teknis di bidang peningkatan Sumber Daya Tenaga Kesehatan, registrasi dan akreditasi tenaga dan sarana kesehatan;

d. Pelaksanaan penelitian dan pengembangan di bidang kesehatan.

e. Pelaksanaan hubungan kerja sama dengan instansi pemerintah, lembaga swasta dan organisasi kemasyarakatan dalam pelaksanaan tugas;

f. Pengawasan dan pengendalian internal pelaksanaan program-program kesehatan;

g. Pembinaan terhadap Unit Pelaksana Teknis Dinas (UPTD);

h. Pengelolaan Ketatausahaan;

i. Pelaksanaan pembinaan operasional di bidang kesehatan sesuai dengan ketentuan yang berlaku;

Untuk melaksanakan fungsinya, Dinas Kesehatan yang mempunyai Kewenangan untuk:

a. Penetapan pedoman penyuluhan dan kampanye kesehatan;

b. Pengelolaan dan pemberian izin sarana dan prasarana kesehatan khusus seperti rumah sakit jiwa, rumah sakit kusta, dan rumah sakit kanker; 
c. Melakukan sertifikasi teknologi kesehatan dan gizi;

d. Melakukan survailance epidemiologi serta penanggulangan wabah penyakit dan kejadian luar biasa;

e. Menempatkan tenaga kesehatan strategis, pemindahan tenaga kesehatan tertentu antar Kabupaten/Kota serta penyelenggaraan pendidikan tenaga dan pelatihan kesehatan;

f. Merencanakan dan mengendalikan pembangunan regional secara makro di bidang kesehatan;

g. Melakukan penelitian bidang kesehatan yang mencakup wilayah Propinsi.

Untuk menjalankan semua tugas dan fungsi dinas kesehatan tersebut diperlukan peranan kepala dinas kesehatan sebagai pimpinan yang kreatif dan dinamis sesuai dengan kewenangan yang dimilikinya. Apabila menelaah dan menganalisa tugas, fungsi dan kewenangan yang ada pada dinas kesehatan maka diperlukan seorang pemimpin yang betul-betul memahami ilmu kesehatan, menejemen dan teknologi tentang kesehatan. Apabila dinas kesehatan dipimpin oleh kepala dinas yang tidak mempunyai kompetensi pada bidang kesehatan maka akan dikhawatirkan perananya dalam meningkatkan kualitas pelayanan kesehatan akan tidak efektif.

Dalam teori kepemimpinan, pemimpin harus mempunyai kompetensi dibidangnya dan bukan hanya mempunyai kompetensi tetapi harus kreatif dan mempunyai naluri yang kuat sebagai pemimpin sehingga ia bukan hanya mampu menjalankan pekerjaannya tetapi ia juga mampu membawa perubahan kearah yang lebih kepada lembaga dan orang-orang yang dipimpin. Hal ini sesuai dengan teori kepemimpinan Extraordinary Leadership dan teori kepemimpinan yang dikembangkan oleh Jim Collins mengenai Level 5 Leadership.
Dalam model yang mereka sebut sebagai Extraordinary Leadership tersebut, mereka mengemukakan ada 4 (empat) hal yang harus dimiliki oleh seorang pemimpin, yaitu kemampuan atau kapabilitas personal (personal capability), fokus kepada hasil (focus on results), memimpin perubahan organisasi (leading organizational change), keterampilan antar manusia atau interpersonal (interpersonal skills).

Walaupun Aceh adalah suatu wilayah bekas konflik dan bencana tetapi prinsip kepemimpinan yang lebih mengedepankan kompetensi dibidangnya tidak dapat diabaikan. Pimpinan daerah misalnya Gubernur atau Bupati harus mengedepankan kompetensi dan profesionalisme dalam menempatkan seseorang untuk menduduki posisi tertentu. posisi kepala dinas kesehatan yang sangat strategis dalam pengembangan dan peningkatan pelayanan kesehatan di Aceh akan stagnan apabila diisi oleh pihak diluar kompetensi di bidang kesehatan.

Mungkin kepala dinas yang berlatarbelakang disiplin ilmu lain yang memimpin dinas kesehatan bisa bekerja tetapi akan lebih efektif jika dinas kesehatan dipimpin oleh seseorang yang berlatarbelakang ilmu kesehatan karena ia mengetahui secara luas dan mendalam berkenaan dengan kebutuhan-kebutuhan yang berhubungan langsung dengan pelayanan kesehatan. Kepala dinas kesehatan yang berlatarbelakang pendidikan kesehatan akan lebih memahami peranannya, apa yang harus dilakukan dalam mengembangkan pelayanan kesehatan sehinga sesuai dengan standarisasi pelayanan kesehatan yang merupakan acuan standar di semua unit pelayanan kesehatan menjadi kebutuhan yang tidak bisa dikesampingkan. Sehingga layanan yang diberikan kepada masyarakat dapat diberdayakan dan ditingkatkan sesuai dengan ketentuan. 
Setiap pemimpin yang profesional itu harus memiliki sikap, tetapi jangan memaksakan sikap kepada orang lain, justru membantu orang lain untuk menentukan sikapnya sendiri. Jadi di sini ada unsur ketegasan sikap sekaligus pemberdayaan orang lain (empowerment) melalui suatu proses inspirasi dan pembimbingan, tanpa ada suatu pemaksaan. Pencontohan perlu dilakukan, tetapi sangat jauh dari suatu bentuk pemaksaan sehingga pemimpin itu bukan hanya cerdas secara ilmuan tetapi juga cerdas secara emosional dan spritual.

\section{Kesimpulan}

Pada prinsipnya, kepemimpinan itu berkembang setiap hari. Kemampuan memimpin bukan hanya suatu bakat sejak lahir, tetapi sesungguhnya merupakan kumpulan dari berbagai ketrampilan, yang hampir seluruhnya dapat dipelajari serta ditingkatkan. Namun diperlukan suatu proses yang tidak terjadi hanya dalam semalam, karena aspek kepemimpinan sangat banyak: kehormatan, pengalaman, kekuatan, emosional, ketrampilan membina hubungan dengan sesama, disiplin, visi, dan sebagainya. Pemimpin yang sukses adalah orang yang belajar, dimana proses belajarnya berkelanjutan, sebagai hasil dari disiplin pribadi dan ketekunan. Jadi kepemimpinan berjalan dari hari ke hari dimana sasaran setiap harinya haruslah menjadi sedikit lebih baik atau membangun di atas kemajuan hari sebelumnya.

Pemimpin dalam satu unit kerja seperti Kepala Dinas Kesehatan harus mampu mewujudkan perubahan dilingkungannya, membangun komunikasi yang efektif, membuat sistem dan jaringan kerja yang efektif, mampu mempengaruhi orang, menerima keragaman, mempunyai komitmen, keteladanan, kedisiplinan, kepamrihan kerja, keoptimisan, tindakan saling mengasihi, dan kekonsistenan yang saling berdampak positif terhadap kepemimpinan dan berdampak balik serta berakumulasi.

Kepala Dinas Kesehatan di Aceh idealnya mempunyai kompetensi dibidang ilmu kesehatan. Efektifitas kerja pimpinan akan diukur salah satu dari kompetensi keilmuannya, ini sesuai dengan teori kepemimpinan yang dikemukakan oleh Jim Collins mengenai Level 5 Leadership dan David McClelland dan Lyle M. Spencer dengan teori Extraordinary Leadership yang menitik beratkan kepada kompetensi atau kapabilitas personal.

\section{Daftar Pustaka}

1. Undang-Undang Dasar 1945 Pasal 28H, ayat 1 : Setiap orang berhak hidup sejahtera lahir dan batin, bertempat tinggal, dan mendapatkan lingkungan hidup yang baik dan sehat serta berhak memperoleh pelayanan kesehatan.

2. Undang-Undang Republik Indonesia No. 36 Tahun 2009 tentang Kesehatan.

3. Armstrong M. Manajemen Sumber Daya Manusia. Terjemahan oleh Sofyan Cikmat dan Haryanto. Jakarta: PT Elex Media Komputindo, 2013.

4. John M. Developing the Leaders around You. Nashville: Nelson, 1995.

5. Kadarusman D. Natural Intelligence Leadership: Cara Pandang Baru Terhadap Kecerdasa dan Karakter Kepemimpinan. Jakarta: Raih Asa Sukses, 2012.

6. Davis K, Newstrom. Perilaku dalam Organisasi. Jakarta: Erlangga, 1995.

7. Wirawan. Evaluasi Kinerja Sumber Daya Manusia Teori, Aplikasi, dan Penelitian. Jakarta: Salemba Empat, 2009.

8. Moenir. Manajemen Pelayanan Umum Indonesia. Jakarta: Bumi Aksara, 2002.

9. Goleman M, Boyatzis. Primal Leadership: Realizing the Power of Emotional Intelligence. London, 2002. 
10. Goleman D. Kecerdasan Emosi untuk Mencapai Puncak Prestasi. Jakarta: Gramedia Pustaka Utama, 1999.

11. Vroom VH, Philip WY. Leadership and Decision Making. Pittsburgh: University of Pittsburgh Press, 1973.

12. Hersey P, Kenneth HB. So You Want to Know Your Leadership Style?. Training and Development Journal, 1974.

13. Blake RR, Mouton JS. The Managerial Grid. Houston: Gulf, 1964.

14. Collins J. Good to Great. New York: Harper Business, 2001.

15. Zenger JH, J Folkman. The Extraordinary Leader: Turning Good Managers into Great Leaders, New York: McGraw Hill, 2002.

16. Covey SR. Principle- Centered Leadership. London: Simon \& Schuster, 1990.
17. Undang-Undang Republik Indonesia No. 23 Tahun 2014 tentang Pemerintahan Daerah (Undang-Undang Republik Indonesia No. 9 Tahun 2015 tentang Perubahan Kedua Atas UndangUndang Republik Indonesia No. 23 Tahun 2014 tentang Pemerintahan Daerah).

18. Undang-Undang Republik Indonesia No. 44 Tahun 2009 Tentang Rumah Sakit.

19. Undang-Undang Republik Indonesia No. 11 Tahun 2006 Tentang Pemerintah Aceh (UUPA).

20. Qanun (Peraturan Daerah) Aceh No. 4 Tahun 2010 tentang kesehatan. 